\title{
A Business Process Model for IT Management Based on Enterprise Architecture
}

\author{
Jonas Montilva, Judith Barrios, Isabel Besembel \\ GIDyC Group, Department of Computing \\ EISULA, Universidad de Los Andes \\ Mérida, Venezuela \\ jmontilva@ula.ve,ijudith@ula.ve,ibc@ula.ve \\ and \\ William Montilva \\ BIOSoft C. A. \\ Mérida, Venezuela \\ wmontilva@biosoftca.com
}

\begin{abstract}
The successful application of Information Technologies (IT) in an organization depends on the business processes used for managing such technologies. It is widely recognized that the use of the Enterprise Architecture (EA) practice for organizing these technologies into a framework is a key factor for achieving a better IT - business alignment. This article presents a business process model for the IT Management that can be used in medium and large organizations as a framework for modelling and analysing their IT management processes. The main difference between the described model and others found in the literature is that our model places EA concept at the centre of the organization of IT Management activities. It provides a better definition, organization and comprehension of the essential and support IT management activities. The described model is being used in several organizations as a referential framework to improve their current IT Management processes.
\end{abstract}

Keywords: IT management, Enterprise Architecture, Business Process Management (BPM)

\section{Introduction}

Information technologies (IT) play, today, a strategic role in the majority of public and private organizations. The success of an organization, in a global economy and interconnected world, depends on these technologies and the way they are managed.

The alignment between business and IT, the frequency of the technological changes and the lack of understanding of business processes by the IT staff are three of the most common problems that an IT manager must face [1].

Enterprise Architecture (EA), seen as a management practice, has won a lot of attention and importance in recent years [2,3]. Its main contribution is in solving the three problems aforementioned. The implementation of this practice, in an organization, leads to a product of the same name - an enterprise architecture, which is defined as "a description of the goals of an organization, how the goals are realized by business processes, and how these business processes can be better served through [information] technology" [3]. An important aggregate value of EA is to provide, to the IT management, with a better understanding of the business processes, their supporting information systems, and the IT platform used to implement and operate these systems.

In this article, we define IT Management as a set of business processes whose main objectives are to plan, implement, operate, maintain, and improve the enterprise architecture of an organization. In most medium and large companies, this process is executed by an organizational unit that is positioned at the highest hierarchical managerial level. To refer to this organizational unit we will use, in this article, the term "IT Department".

According to the proposed definition, the EA must be the center of attention of an IT department. The components of this architecture are the resources or the business objects that an IT department must manage.

An enterprise architecture is a description of the following components or elements of a company or organization (or of a part of it):

- The objectives of the business, its business processes, and activities, its actors and its business rules; 


\section{CLEI ELECTRONIC JOURNAL VOLUME 17 NUMBER 2 PAPER 3}

- The information systems that the company needs to run these business processes; and

- The software, hardware, and network platforms or infrastructures, on which the information systems are developed, installed, and managed.

These components determine three levels or layers called: Business Architecture, Information Systems Architecture, and Technology Architecture, respectively.

The concept of EA is not new. It has been used since the decade of the 80s with the well-known framework of Zachman [4]. However, it is in the last few years that this concept has gained increasing importance. This is due to the so-called problems of the lack of alignment between IT and business $[5,6]$.

These problems have led to the resurgence of the EA as a discipline that has created a set of reference models, methods, and bodies of knowledge; among which are the frameworks TOGAF [2], DODAF [7], TEAF [8], and the body of knowledge EABOK [9]. These models and frameworks provide a comprehensive overview of the concepts, processes, and resources that an IT department is required to manage.

In parallel to the evolution of EA, different models have emerged that prescribe specific IT management processes. The most prominent ones are: ITIL V3 [10], CMMI-Dev [11], COBIT [12], and DAMA [13]. The first of them is oriented toward the management of IT services; CMMI-Dev focuses on software development processes; COBIT proposes a set of control objectives of particular importance for IT governance; meanwhile, DAMA describes a process model for data management. None of them covers, by itself, all the processes that an IT department should execute.

The IBM Process Reference Model for IT [14] is an exception. It provides a set of methods and techniques for identifying and improving all areas associated with IT within an organization. Based on the IBM extensive IT management experience, this model extends ITIL [10] through the incorporation of service management practices into IT management processes. This model groups all IT management processes into eight categories: governance and management, customer relationships, direction, realization, transition, operations, resilience, and administration. The description of the internal management processes and their interrelationships lets IT managers improve the control and implementation of IT processes; which facilitates the IT alignment with the objectives and priorities of the organization. Being an extension of ITIL, this model is based on a service management approach to IT management. The notion of enterprise architecture is completely absent in the structure of this model.

The objective of this article is to describe a comprehensive and integrated process model for IT management based on the EA approach. This approach provides a complete and well-structured framework that facilitates the integrated management of the three levels of an enterprise architecture: the business architecture, the information systems architecture and the technology architecture.

In addition to using the enterprise architecture as the focus of attention of IT management, our model is distinguished from the aforementioned models and frameworks in two aspects. Firstly, we use a value chain to divide IT management processes into two separated groups of processes: fundamentals processes to EA management and supporting processes. Secondly, IT management processes are modeled as a set of business process using a well-known UML extension to business. By doing so, the set of IT management processes may be seen and treated as a constituent part of the Business Architecture.

The rest of this article is organized as follows: Section 2 describes the Business/IT Alignment as one of the main problems that IT managers must face today. Section 3 presents a summary the main EA concepts. Section 4 describes our process model to IT management. Each process of our model is described, with the detail that the page limit of the article allows, in sections 5 and 6. Finally, section 7 discusses the contribution of the model and its applicability in medium and large organizations.

\section{The Business/IT Alignment Problem}

The alignment of IT to business has been one of the main concerns of many IT managers for more than two decades. Since 2004, this problem has been ranked among the top studies that measure the importance of the concerns of IT managers and CIOs. It has been shown that companies that achieve greater benefits of productivity, performance and presence in the market are those that are able to take advantages of technologies and align IT to business [15$18]$.

It is clear that the search for a good level of alignment, between business objectives and the technologies that support them, has transformed the way IT management is conducted today in many organizations. This occurs not only at the level of strategies for the optimal use of technologies and resources already in place (for example, legacy 


\section{CLEI ELECTRONIC JOURNAL VOLUME 17 NUMBER 2 PAPER 3}

systems, support infrastructure, etc.), but at the level of the specification for the new technologies that are required to support business processes that contribute successfully to the achievement of strategic objectives.

In addition, the speed at which IT evolves increases the complexity of this alignment, because there is not enough time to assimilate the new technological changes. It is a fact that changes in IT cause, in turn, changes in the way of working and in the organization of business processes. On the other hand, changes in business strategies - to conform to the globalized world - produce changes in the business processes, which in turn, cause changes in the technologies required to perform these processes. The implementation of new and more advanced technologies usually requires the restructuring of the processes and activities needed to manage them. This situation creates a kind of cyclic relationship cause-effect-cause that the organization must manage in a strategic way.

It is important to mention that the strategic goals are also temporary, with a horizon that does not go beyond to three or four years. This is due to the influence of the changing and competitive global environment that totally depends on information technologies. That is the main reason for extending the alignment problem reached in an instant of time, to an ongoing maintenance of this alignment throughout a longer period of time. The problem of safeguarding the evolution of the links between the business and the technology, called in the literature the coevolution of the alignment Business/IT, has been treated from different and complementary perspectives $[19,20]$.

In the context of this article, we understand by business/IT alignment, the establishment of parallel and progressive links, among certain elements of the business (specifically, strategic goals and key processes), and those technological elements that support the achievement of the strategic goals; i.e., the information systems, the data and the IT infrastructure. Whole elements are considered the primary components of what is called the Enterprise Architecture (EA) of an organization.

According to the previous paragraphs, the problem of strategic alignment between business and IT is an arduous and complex task. Consequently, our proposal establishes that an appropriate business/IT alignment must be based on the interdependent and complementary knowledge specified inside an EA. Thus, any variation in the organizational needs, strategies, processes and activities, will be immediately captured and analyzed to establish what effect, and consequent change, must be carried out in current links with Information Systems, Data and IT.

The IT department has the responsibility of planning, implementing, and operating and continuously improving the enterprise architecture of its organization; so that the enterprise architecture can provide the IT services that the organization needs. It is also the responsibility of this unit, to maintain the enterprise architecture aligned with the strategies and goals of the organization. Subsequently, the specification of a business processes model that describe the integrated set of technical, administrative and management processes of an IT department, is essential. This business process model will lead to directly achieve the goals of the IT department, and complementary, it will lead, indirectly, to reach the goals and strategies defined for the whole organization.

Currently, the alignment business/IT has been studied from alternative points of view; which go from management throughout operational perspective proposals where various authors describe the crucial technical details of systems and technologies [21-23]. Some of these studies are based on standards and reference models such as: COBIT, ITIL, CMMI, ISO 9000:2007, etc., where the studies specify practices, processes for controlling technologies, and heuristics based on case studies. However, these proposals are, in a certain way, independent and do not cover all the categories of processes that are carried out in any IT department.

As we pointed out, in an IT department there are typical processes such as management of technical and operational issues, as well as processes related with the governance of the information systems and technology resources; but, other management processes, such as the management of technical or specialized human resources, financial resources, physical infrastructure, and administrative management of risks, are not integrated in the above mentioned studies or proposals.

On the other side, we find that EA has been used as a base for the governance of technologies and for the definition of the information systems of an organization [5], [24]. However, we have not found in the literature of the area, results of research or practice related to the specific use of the relationship between the EA and the business processes executed by the IT department of an organization.

Considering that the IT department is responsible for defining, operating and maintaining the enterprise architecture of an organization, the practical use of this critical relationship remains the main contribution of this work. We believe that there is a direct dependence between the implantation of a specific business processes model for the organizational unit responsible for the enterprise architecture, and the positive and effective role that will play this EA in the achievement of the alignment between business, IT technologies strategies and policies. 


\section{CLEI ELECTRONIC JOURNAL VOLUME 17 NUMBER 2 PAPER 3}

The model of IT management processes described in this article is an integrated set of the essential managerial and technical processes that an organization should implement in order to carry out an efficient and effective management of the EA resources (modeled, created, contained, and supervised) within an organization.

\section{Enterprise Architectures}

An enterprise architecture is a description of the business objectives of an organization, how these objectives are achieved through business processes and how these business processes can be supported through the use of IT [3].

The enterprise architecture is represented by a set of models that describes and relates the business objectives, the business processes, the information systems and the IT platform and that will be required to support the business processes of an organization or a part of it.

\subsection{Components of an enterprise architecture}

As shown in figure 1, an enterprise architecture is composed of three levels or layers. The top layer, called the Business Architecture, describes the organization (or a part of it), its objectives, its business processes, its actors, its business rules, and its organizational structure, among others. The middle layer is known as the Information Systems Architecture. It describes the software applications and the data repositories (e.g., databases, files, data warehouses, etc.) that the organization uses to support its business processes. The lower layer is identified as the Technology Architecture. This layer provides details of the software, hardware and telecommunications platforms, on which the information system layer is developed, installed, and operated.

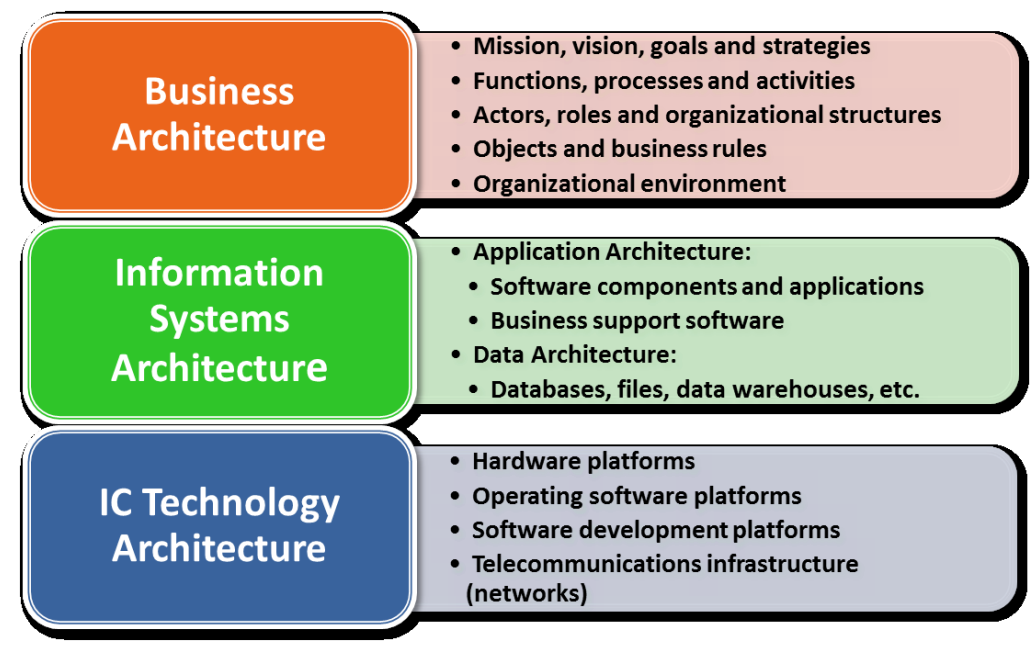

Figure 1: Levels of an enterprise architecture

The location of the layers defines the relations of dependence between architectures. The Information Systems Architecture is developed and operated with the support of the Technology Architecture. The Business Architecture is composed by business processes that are supported by the Information Systems Architecture. These relationships are crucial to ensure the proper alignment between the business, its information systems, and its IT platform.

\subsection{States of an enterprise architecture}

The enterprise architecture of an organization is represented at two different instants of time: current and future. These moments determine two different states of the architecture, as shown in figure 2. At the current moment, the enterprise architecture is described as it is by the time the EA planning is in progress. This state defines the baseline of the enterprise architecture. At the future moment, the enterprise architecture is described as it is targeted, that is, as it should be implemented in the next 3-5 years. 


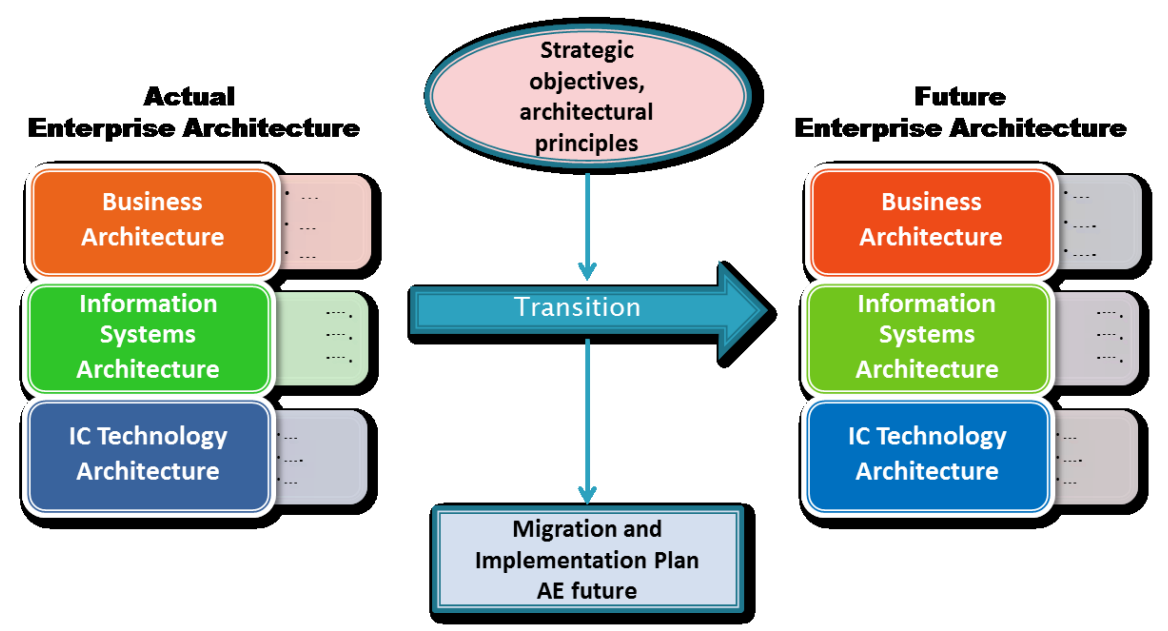

Figure 2: States of an enterprise architecture

The Baseline Enterprise Architecture represents the current state of the organization, its systems, and its technological infrastructure.

The Target Enterprise Architecture is a design of the architectures of the business, information systems and of IT that the organization should possess in the next three or four years, as it is required in order to meet the objectives set out in their strategic plans. This architecture is designed on the basis of:

(1) the strategic objectives that the company hopes to achieve in the long term; and

(2) the architectural principles that should guide the design of the target architecture.

A migration and implementation plan guides the transition from the baseline state of the enterprise architecture to its target state. This plan organizes and describes the portfolio of projects, as well as the activities, schedule, and resources that are required to make the transition between the two mentioned states.

\subsection{IT Management and Enterprise Architectures}

IT Management is a managerial process through which an organization plans, develops, operates, and constantly improves its enterprise architecture, with the objective of providing the IT services that the organization requires.

One of the most important objectives of the IT Management is to achieve a high degree of alignment between business and IT. IT managers must therefore ensure that the information systems, and the IT platform on which these systems operate, provide the effective support that business processes demand for achieving the strategic objectives of the organization, as established in the business plans.

In order to achieve effectively this objective, EA must become the focus of attention of IT managers and CIOs. IT Management must be centered on managing the enterprise architecture.

In the next sections, we describe an IT process model that is based on the close relationship that must exist between EA and IT Management.

\section{The Process Model for IT Management}

A process model for the IT management is a description of the set of business processes, and their activities, that the IT Management of an organization is required to execute, in order to fulfill its business objectives, and deliver the IT services that the organization demands.

The model that we describe in this section is based on the following premise: The main responsibility of the IT Management of an organization is to manage effectively and efficiently the enterprise architecture of that organization, in order to provide the IT services that the organization demands.

Managing an enterprise architecture involves a set of business activities, such as planning, implementing, operating, evaluating and improving the enterprise architecture and its three main components: the business 


\section{CLEI ELECTRONIC JOURNAL VOLUME 17 NUMBER 2 PAPER 3}

architecture, the information systems architecture and the technology architecture. Using the EA structure as a framework, these activities can be organized and grouped into processes using a value chain, as illustrated in Fig. 3.

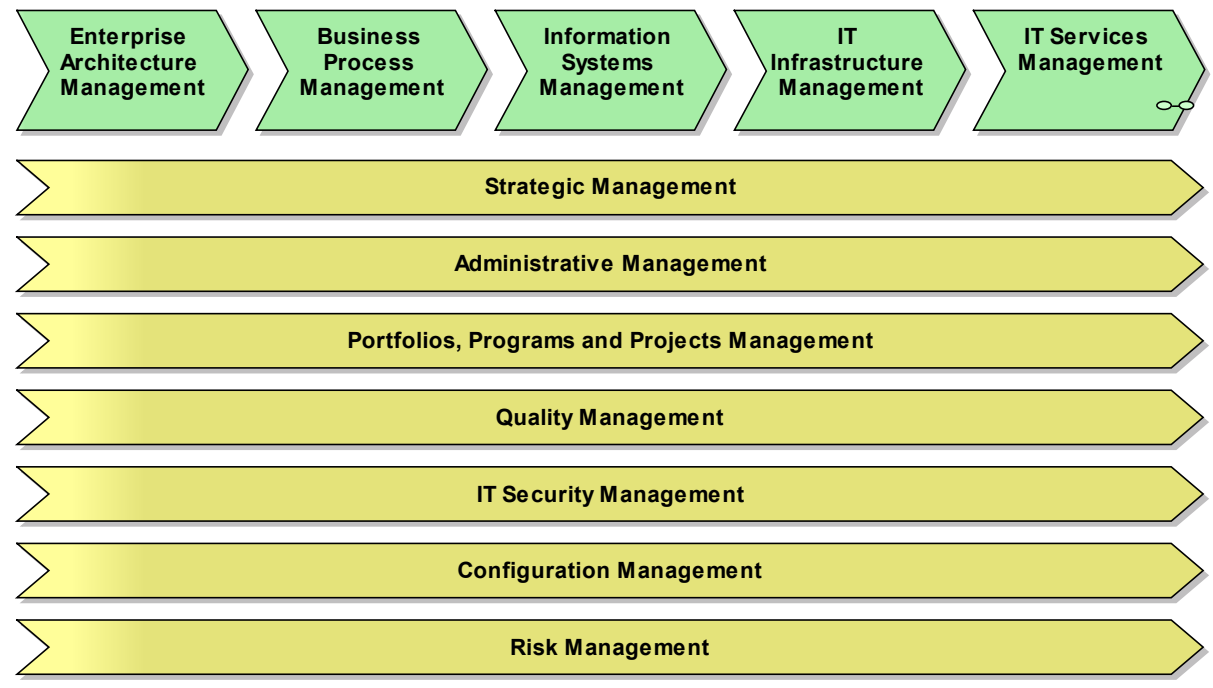

Figure 3: IT Management Value Chain

The value chain of an organization is a process model that organizes the business processes that directly generates customer value and differentiates these processes from those that support indirectly this generation of value. The first ones, called essential or primary processes, justify the existence of the organization and allow it to achieve its business goals; the second ones offer the support needed to execute the essential or primary processes.

The essential processes are located at the top of the value chain and organize the set of activities that are the raison d'être of the IT Management. These processes are: Enterprise Architecture Management, Business Processes Management, Information Systems Management, IT Infrastructure Management and IT Service Management.

The support processes, located at the bottom of the value chain, group administrative and technical activities that are necessary to facilitate the execution of the activities of the essential processes. This group includes the following processes: Strategic Management, Administrative Management, Portfolio, Programs, and Projects Management, Quality Management, IT Security Management, Configuration Management, and Risk Management.

Each of these processes is described, succinctly, in the following sections of this article.

\section{The Essential Processes of IT Management}

\subsection{Enterprise Architecture Management}

This process is responsible for the planning, implementation, improvement and governance of the enterprise architecture as a whole. The decomposition of this process into a hierarchy of lower level processes is presented in Fig. 4.

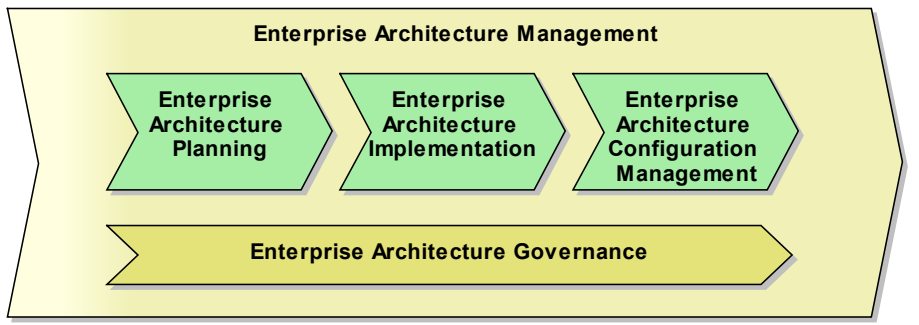

Figure 4: Enterprise Architecture Management Processes 


\section{CLEI ELECTRONIC JOURNAL VOLUME 17 NUMBER 2 PAPER 3}

EA Planning consists of three groups of activities: (1) the definition of the baseline enterprise architecture; (2) the definition of the target enterprise architecture, and (3) the process of planning the migration from the baseline to the target architecture. The main products of this process are the set of models that describes the baseline and target architectures and the EA Migration and Implementation Plan (EAP). The latter is a long-term plan that contains the portfolio of programs and projects needed to implement the target enterprise architecture.

EA Implementation is the management process responsible for coordinating, supervising and controlling the execution of each one of the projects defined in the portfolio of the EA Migration and Implementation Plan.

EA Configuration Management is the process of managing the changes to the baseline and target architecture and to the components of the EA portfolio. It is also in charge of creating, managing, and maintaining the Architecture Repository which is used to organize and store all the documents and products of the EA processes and endeavors.

The EA Governance process exerts an appropriate direction, and control over the planning, implementation, and evolution (improvements) of the enterprise architecture.

\subsection{Business Processes Management}

This process focuses on the Business Architecture. It consists of the representation (modeling), analysis, evaluation, and improvement of the business processes of the organization. It is divided into the set of processes shown in Fig. 5 .

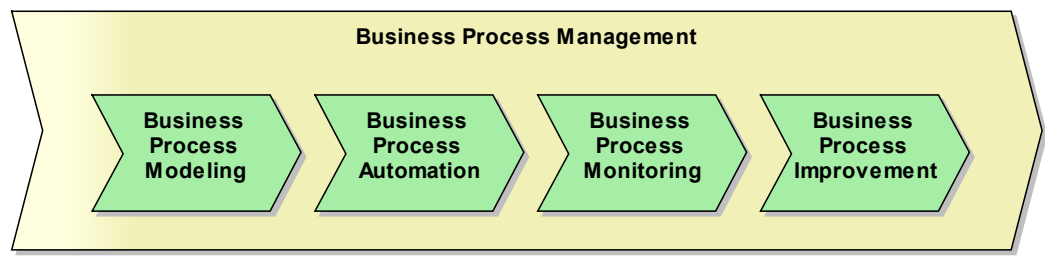

Figure 5: Processes of the Business Processes Management

The main product of the Business Processes Management is the set of models that represent the processes that the organization should execute to achieve its goals. These models describe different organizational elements, such as business objectives and goals, business processes and their activities, the actors that execute these activities, the business rules that the processes must comply, and other elements that characterize the organization as a business system [25].

These models are elaborated using appropriate modelling notations or languages, such as BPMN [26], and the extension of UML to business of Eriksson and Penker [27].

Several of the business processes can be automated using suitable languages and tools for Business Process Management (BPM). Both manual and automated business processes need to be constantly monitored in order to evaluate its effectiveness and determine the need for improvements.

\subsection{Information Systems Management}

It includes all technical and operational activities that are needed for the implementation, operation, maintenance, and governance of the information systems architectures: the Applications Architecture and the Data Architecture. This process is responsible, therefore, of:

- The development, operation and maintenance of the information systems of the organization, including software components (e.g., web services, EJBs, .NET components, etc.), business and support applications, and data repositories (e.g., files, metadata, data bases, data marts, etc.).

- The governance of information systems which is responsible for the direction and control of all the activities associated with managing, operating, and maintaining the information systems.

The Information System Management process is divided into three lower level processes, as shown in Fig. 6. 


\section{CLEI ELECTRONIC JOURNAL VOLUME 17 NUMBER 2 PAPER 3}

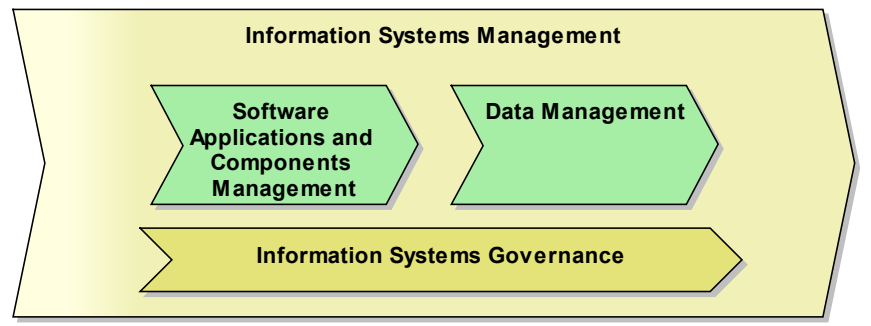

Figure 6: Processes of Information Systems Management

\subsubsection{Software Applications and Components Management}

This process is responsible for the technical and support activities that are needed to develop, administer, and maintain all the applications and reusable software components that make up the Information Systems Architecture (see Fig. 7).

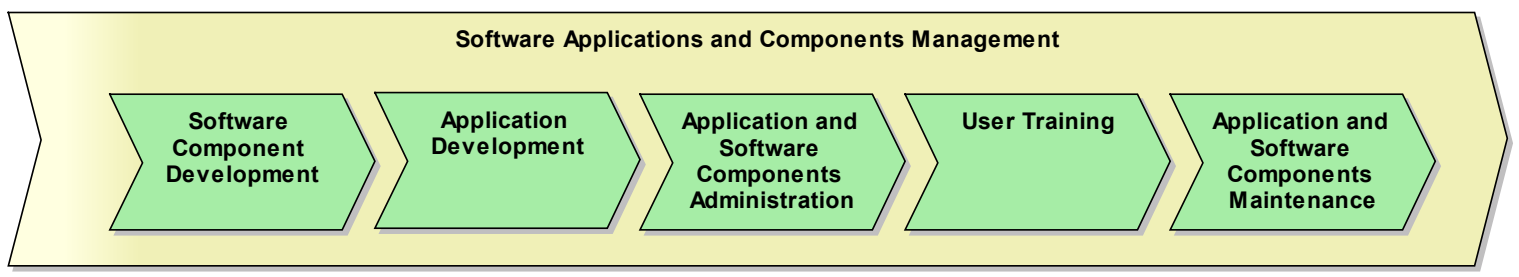

Figure 7: Processes of Software Applications and Components Management

Like most of the other processes in the model, this one is decomposed into one or more hierarchical levels until the lowest level of abstraction is reached. An example of one of the low-level process diagram is shown in Fig. 8.

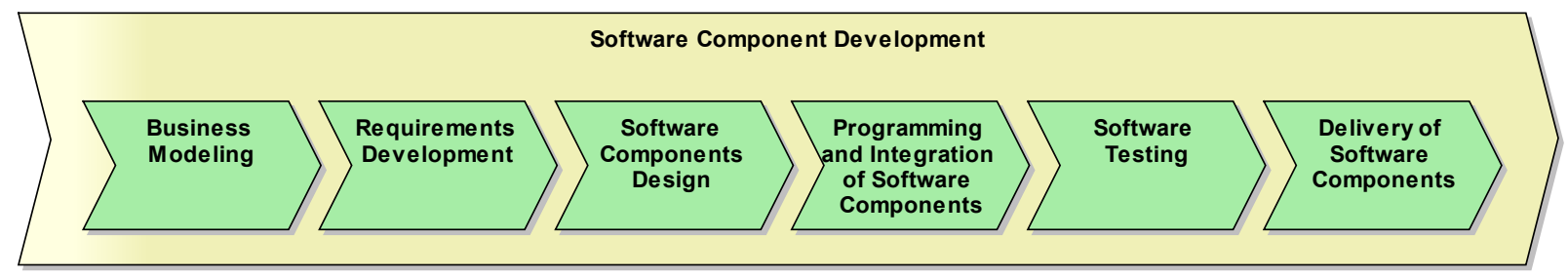

Figure 8: Processes required for developing software components

Each process of the lowest level of abstraction is described, in our model, using a UML process diagram, as exemplified in Fig. 9. 


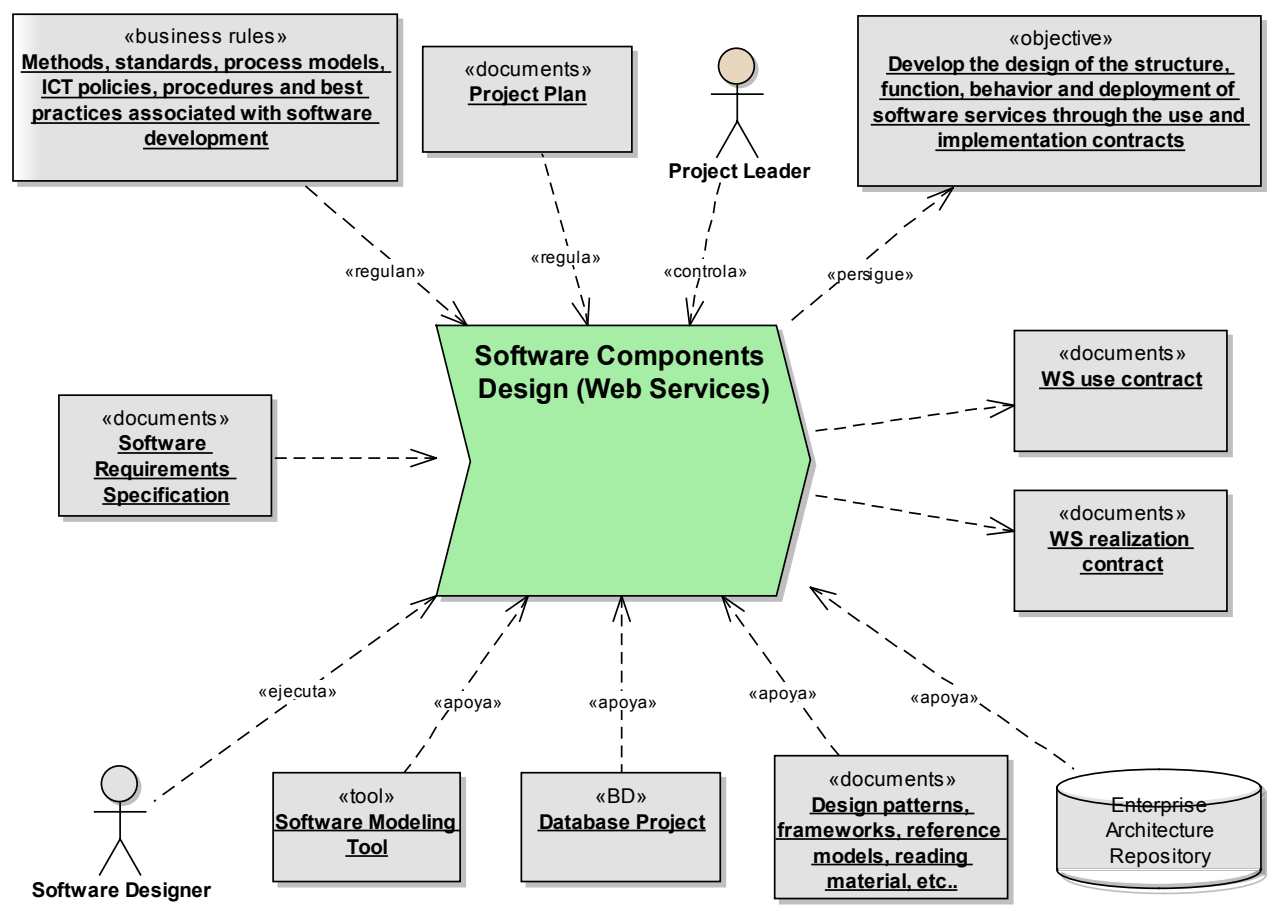

Figure 9: A low-level process description

Our model promotes software reusability. Application Development is, therefore, a process that is executed in parallel to Software Components Development. Both processes produce software solutions based on the assembly of reusable components, such as web services and EJB components.

These two processes are independent of the existing methodological approaches (i.e., agile, balanced, disciplined, waterfall, evolutionary, etc.). Our process model identifies and brings together the activities of software development without indicating or encouraging the use of any method or practice. The selection of methods, practices, standards and procedures that are required, in any of the processes, is beyond the scope of the model.

\subsubsection{Data Management}

This process is about planning, implementing and monitoring policies, practices and projects that enable to gather, manage, protect, deliver, and improve the value of the data and information.

Data Management is intended to meet the needs of data and information of the organization and its stakeholders or users, ensuring the availability of the data, the continuous improvement of the quality of the data and information, as well as the privacy, confidentiality and access control to these business assets.

The management of data uses the architectural principle that considers to data and information as assets or corporate resources [2]. Data Management is executed, therefore, separate from the management of applications and software components. Fig. 10 shows the technical processes that make up the Data Management process. This process decomposition is based on the body of knowledge of Data Management DAMA-DMBOK [13]. To the best of our knowledge, DAMA is the only data standard published until now. One of its main features is that it highlights the differences and clarifies core data concepts, such as metadata, master data, and reference data. 


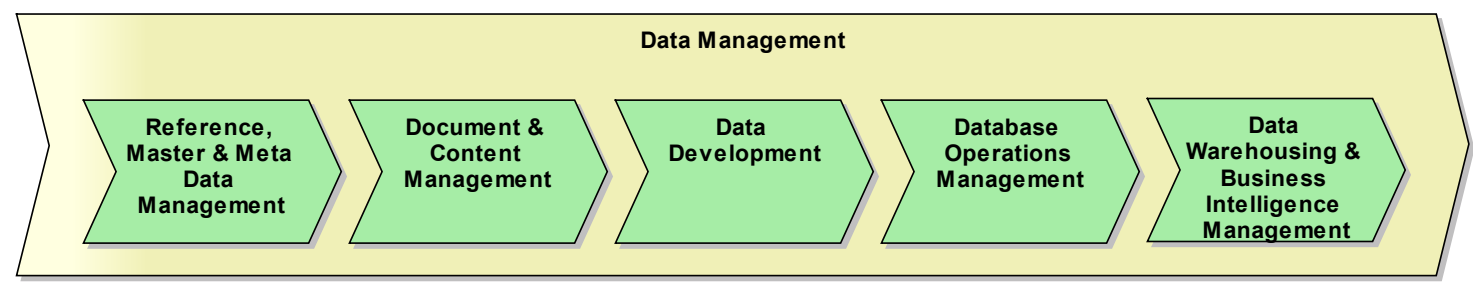

Figure 10: Data Management Processes

\subsubsection{Information Systems Governance}

It is transversal to the processes of managing applications, software components and data. It is responsible for the direction and integrated control of the Information Systems Management processes.

\subsection{IT Infrastructure Management}

This process is responsible for the operational management of the IT infrastructure as defined by the Technology Architecture. This infrastructure includes the set of hardware, software, network and telecommunication technologies employed to support the development, installation, operation, maintenance and interaction between the components of the Information Systems Architecture. It is divided into the processes identified in Fig. 11.

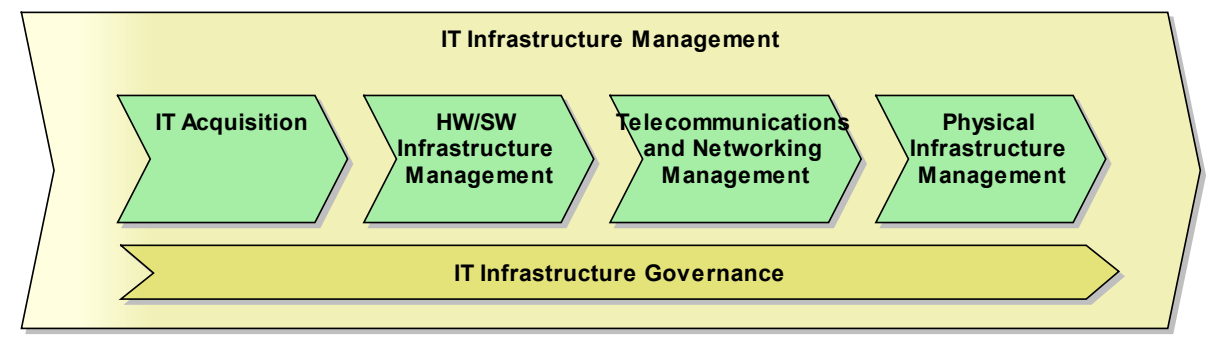

Figure 11: Processes of IT Infrastructure Management

IT Acquisition consists of the selection, purchase, installation and replacement of the hardware, software and telecommunication products that comprise the IT infrastructure.

All the hardware (HW) and system software (SW) that the organization owns is a subset of the IT infrastructure. The HW/SW Infrastructure Management process includes a set of activities to define, install, operate, monitor and maintain the hardware/software platforms of the organization.

This process also includes all those activities that are concerned with the management, operation and maintenance of the organization's data center.

Telecommunications and Networking Management covers all activities related to the installation, operation, control and security of the telecommunications and networks infrastructure of the organization. Its aim is to ensure that all networks of the organization operate efficiently and provide a high service availability to their users. It includes processes such as capacity planning, design, installation and configuration, security, control and maintenance of the different types of networks (LAN, MAN or WAN).

Physical Infrastructure Management is related to the administration and maintenance of the physical environments in which the IT Infrastructure of the organization is installed, operated, monitored and maintained. It includes the processes and activities needed to manage the electrical and mechanical subsystems that the Data Centers and any other IT installation require.

IT Infrastructure Governance comprises the activities of planning, coordination, direction and control of the resources that are involved in processes and projects of the IT infrastructure. 


\section{CLEI ELECTRONIC JOURNAL VOLUME 17 NUMBER 2 PAPER 3}

\subsection{IT Services Management}

An IT Service is an intangible non-storable product that is generated by one of the IT Management processes with the purpose of responding to requests made by internal or external users of the organization. Are examples of IT services the following: the creation of an e-mail account, the generation of a management report, and the solution of a problem in the use of an application.

As shown in Fig. 12, the IT Services Management processes used by our model are based on the ITIL V3 standard [10]. We choose this de facto standard because of its particular point of view in considering different types of events like incidents, problems, request, and events they self. According to Dugmore and Taylor [28], this is one of the differences with the ISO/IEC 20000, which considers all of them in its resolution processes, but without making particular differences between them. Another IT standard is the Application Services Library (ASL). Meijer, Smalley, and Taylor [29] point out that "ITIL describes processes and activities that are common to both models in more detail than ASL". In our perception, both standards may be considered, but in our Latin-American environment ITIL is more known than ASL.

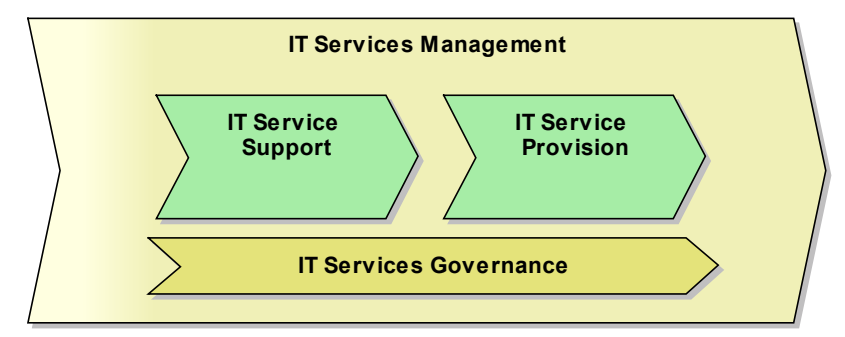

Figure 12: IT Service Management Processes

This process can be implemented using call centers and/or service desks. A call center is able to handle a high volume of calls. It may redirect the user to other levels of support in case that it may be needed. A service desk is a set of services that offers the ability to manage and solve all the potential incidents in a holistic manner, including the attention of new requirements related to information systems and/or the IT infrastructure. A service desk represents an interface for clients and users of all IT services that the IT Management offers.

In both implementations, the concept of Service Level Agreement (SLA) is used. It sets out the conditions for the provision of services.

\subsubsection{IT Service Support}

IT Service Support process is concerned with those activities that guarantee the continuity, availability and quality of the services provided to the users. These activities are organized in processes as indicated in Fig. 13.

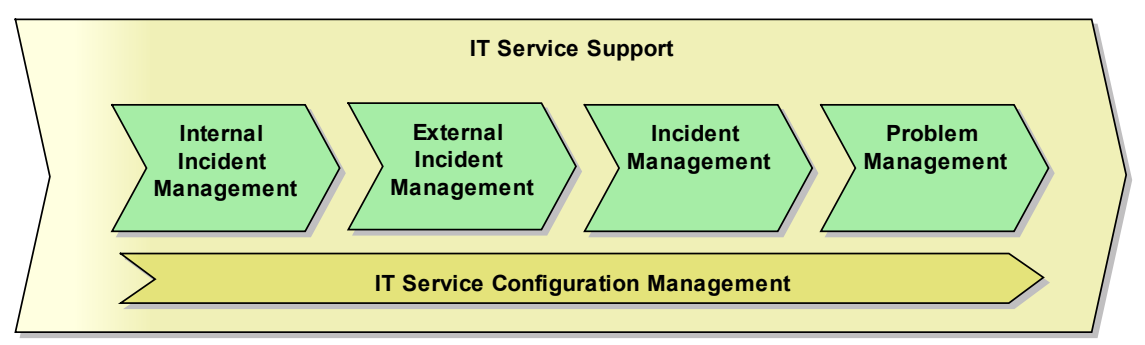

Figure 13: IT Service Support Processes 


\section{CLEI ELECTRONIC JOURNAL VOLUME 17 NUMBER 2 PAPER 3}

\subsubsection{IT Service Provision}

This process deals with the IT services themselves as they are offered to their users. It takes into consideration the SLAs, the availability of the services, the service continuity, the service financial viability, the capacity of the IT infrastructure and the levels of security required. Fig. 14 shows the set of processes associated with the provision of IT services.

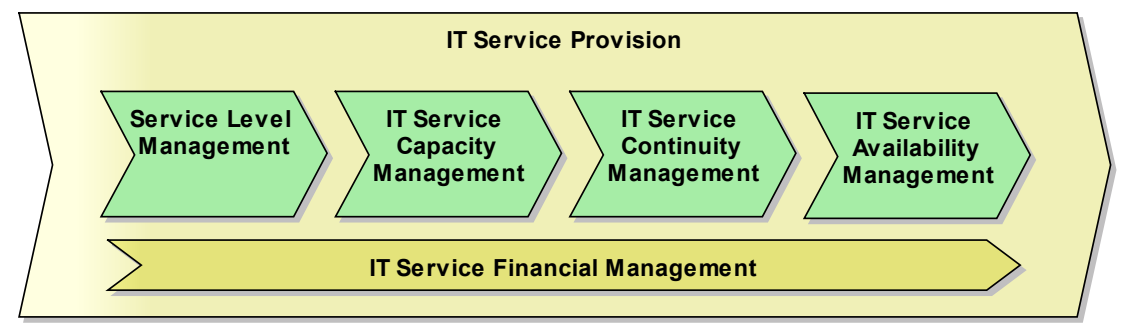

Figure 14: IT Service Provision Processes

IT Service Governance is transversal to the processes of service support and service provision. It is responsible for the direction and integrated control of these two processes.

\section{The Support Processes of IT Management}

The fundamental processes, described above, are supported by a set of administrative and management activities, which contribute to the effectiveness and efficiency of such processes. These activities are organized in the so-called support processes, located in the lower part of the value chain of the IT management model (see figure 3).

Several of the support processes are specialized to provide better sustain for fundamental or support processes. Such is the case of the Configuration Management, Risk Management and IT Security Management processes. The latter, for example, specializes in management the security of the IT infrastructure, the Data, and the Computing Services.

\subsection{Strategic Management}

It is a management process for aligning the goals of the IT department to the strategic goals of the whole organization. The process consists of a set of activities that lead to maximize or at least to maintain at a high level, the degree of alignment between the implementation of the IT goals and the business goals.

To do that, the strategic management establishes the medium and long-term mission and vision, so it can establish the strategic goals of the business and the IT strategies that allow reaching them. It consists of a set of planning and strategic control activities. It also includes the management of IT policies that will be used to carry out the IT governance. This process is comprised of four sub-processes:

- Strategic Direction. It consists on establishing the internal and external variables that influence both, positively and negatively, in the successful attainment of the goals of the IT Management. These variables assist to determine the main orientation that the organization must follow for defining IT strategic goals; which have to be consistent and cohesive with the strategic goals of the whole organization.

- Establishment of IT Strategies. The process consists on the definition, analysis and selection of IT strategies that lead to implement the strategic goals of the IT Management. IT strategies must be in accord with business strategies. This process includes the processing and inclusion of strategies within the framework of the current and future EA. Among the main activities of this process are: strategic options and functional projects formulation, evaluation of these strategic options and functional projects, and definition of strategies for the IT management.

- IT Policy Management. Policies are documented statements that establish the set of rules associated with the different aspects of the EA. Policy Management is a strategic process that requires the implementation 


\section{CLEI ELECTRONIC JOURNAL VOLUME 17 NUMBER 2 PAPER 3}

of activities related to the definition and development of IT policies, implementation and maintenance of these policies, as well as the establishment of guidelines to eliminate these policies when they no longer support the business strategy.

- Monitoring of IT Strategies. This process measures the degree of effectiveness of the implemented strategies in order to achieve IT goals and strategic projects. This process determines the technical and managerial mechanisms and instruments, considered necessary to measure efficiency and effectiveness of the implemented strategies and to establish mechanisms to improve these strategies, if required. In addition the process comprises the evaluation of the organizational and current EA performance searching to attain a better fit and support of strategic business goals.

\subsection{Administrative Management}

It is responsible for the planning, organization, direction, and control of human, financial, physical, and budgetary resources that are managed by the IT Department.

This process breaks down in the next set of processes:

- Human Resources Management. It is in charge of matters pertaining to staff, the performance evaluation of the staff, and the staff training and development.

- Management of Financial Resources. It is responsible for the management of all of the financial resources, including, among others, the management of contracts, purchases, and costs; as well as, the acquisition of goods, materials, and office supplies, the provision of services, and the processing costs and flow cash.

- Management of Physical Resources. It consists of the control of goods and materials; as well as, the administration and control of documentation that handles the IT Department.

- Budgetary Management. It is responsible for the formulation, monitoring, and control of the budget allocated to IT Management.

\subsection{Portfolio, Programs and Projects Management}

This process is related to the activities responsible for the management of the portfolio of programs and projects described in the EA plan (EAP). The EAP comprises the programs and projects that implement new architectures for information systems and IT.

The standards of the Project Management Institute (PMI) describe how to manage portfolios, programs and projects [30-32]. Our model uses these standards to describe three sub-processes called Portfolios, Program and Projects Management, respectively:

- Portfolio Management. The portfolio is the collection of projects and/or programs defined within the EA that are fundamentals to achieve the strategic business goals. The portfolio reflects the investment undertaken or planned by the IT Management by identifying required priorities, resources and investment. This process includes the set of activities necessary to define and maintain the strategic alignment between an EA and the business, monitor, and control the behaviour of each of the EA components, review their performance, notify risks, and analyze and authorize changes.

- Program Management. A program is a set of related projects that are managed in a coordinated manner to create benefits in pro of attaining the strategic business goals. Thus, the activities required for managing programs include the administration of the relationship between programs and the portfolio of projects, and the administration of risks between projects and programs governance.

- Project Management. An IT project includes the definition, implementation and control of the effort and the resources allocated to deliver a product or a service. Project management involves activities for planning, organizing, directing, and controlling the required and assigned resources of each IT project. It also implies the support activities for coordinate changes that may emerge during project execution. Project Management process is based on the standards, strategies and IT policies established within the organization. 


\section{CLEI ELECTRONIC JOURNAL VOLUME 17 NUMBER 2 PAPER 3}

\subsection{Quality Management}

Is carried out through a Quality Management System, which must be designed, implemented, and properly managed to ensure, monitor, and improve the quality of the products, processes, and IT services.

The Quality Management System has as its main objective to contribute to the achievement of the strategic objectives of the EA plan. It is achieve through the implementation and execution of processes of assurance, control, measurement, and improvement of the quality of the products, processes, and IT services for the IT Department. Its main sub-processes are identified below:

- Quality Assurance. It ensures that the IT management processes are running according to the rules, procedures, and standards established by the organization. In addition to fulfilling the obligations on the quality contracted with users or clients and referring both to the IT services and products.

- Quality Control. It deals with the definition and implementation of measurement methods and standards of measurement and control of the quality of the processes, products, and IT services.

- Continuous Improvement of Products, Processes, and Services. It refers to the continuous improvement of the quality of the processes to ensure compliance with the objectives and policies of quality set forth in the Quality Plan of the organization.

- Quality Governance. It is responsible for planning and controlling the quality of the IT processes, products and services. Its main product is the Quality Plan.

\subsection{IT Security Management}

It groups a set of processes responsible for ensuring the security of the data and information which are handled by the information systems, the IT infrastructure, and the services of the IT Department. These processes are called, respectively, Management of the Data Security, Management of the IT Services Security, and Management of the Technological Infrastructure Security.

The IT Security Management must ensure compliance with three main objectives:

- Confidentiality. It pursues to maintain the necessary protection against unauthorized access to the corporate data and information. It applies to all data (structured, unstructured, documents, and contents) during their storage, processing, and transit.

- Integrity. It aims to ensure that the data is not altered, in an unauthorized manner, during storage, processing, and transit. This goal applies also to other resources or computing assets (applications, hardware, software, and networks), which should be protected from unauthorized modification, not anticipated or accidental.

- Availability. The aim is to ensure, without limitations of time or place, authorized access to the computational resources and services of the organization, avoiding the denial of service to those who have the necessary authorization to access the information or to use the computing services.

\subsection{Configuration Management}

It is responsible for the administration of the EA Repository, which stores all the models and documents related to the enterprise architecture. This process manages, in addition, any changes to these documents and models. It is, also, used to bring the control of changes in the products that are generated in the software development projects and the services provided by the IT Department.

This process takes an up-to-date register of all the elements that configure the EA. This register provides control over the changes and versions of those architectural elements that the organization wants to follow their evolution throughout their life cycle.

To organize the activities of Configuration Management, our model is based on the IEEE standard 828-1998 [33]. The Configuration Management of the EA consists, therefore, of the following processes: 


\section{CLEI ELECTRONIC JOURNAL VOLUME 17 NUMBER 2 PAPER 3}

- Configuration Management Planning. It is responsible for drawing up the plan of each configuration item, specifying its purpose, scope, organization, responsibilities of the actors, phases of the configurations based on their defined baselines, and the documentation of the plan.

- Configuration Identification. It is about the identification of configuration items and the baseline configuration together with their associated databases, as well as documented deliveries or releases.

- Configuration Control. It is responsible for the management of the requested changes to the configuration items. It is responsible for the authorization of these requested changes and the corresponding update of the plan after any change is made.

- Configuration Status Accounting. It records and disseminates the latest state of the configuration items.

- Configuration Auditing. It verifies and validates the EA configuration. This determines each configuration item of the baseline of the product, its version, and the revisions according to the baseline.

- Release Management and Delivery. It controls the distribution or delivery of those products that are under configuration control.

\subsection{Risk Management}

This process supports the processes in the value chain (see figure 3) that require to control the risks that may affect the components of the information system and IT architectures. Risk management is applicable also to projects contained in the portfolio of the IT department.

The proposed model takes and adapts the general processes of Risk Management that recommends the PMI, specifically, in the body of knowledge PMBOK [32]. The selected processes are the following:

- Risk Management Planning. The main goal of this process is to plan the set of risk management activities to carry out. This process is necessary to ensure that the rest of risk management activities are performed effectively and efficiently. Among the activities included in this process are defining methods, tools, techniques and standards that will be used to manage risks of each EA component; developing the work breakdown structure necessary to manage risks within a risk timetable; estimating required resources to manage risks, and outlining the risk management plan.

- Risk Identification. This process determines the risks that can affect different components of the EA and describes the characteristics of each identified risk. This process includes activities to develop checklists of risks, to analyse the characteristics of the EA components, to identify what risks apply to the different EA components, and to develop the risk log describing the identified risks.

- Risk Analysis. Process that leads to establish the priorities of the already identified risks and to determine the probability of occurrence and the impact of each of them over the EA components. The activities of this process include selection of the techniques to prioritize the risks; estimation of the probability of occurrence for each risk; determination of the impact that the risk can have on the EA components; development of the probability and impact of risks matrix, and the updating of the risk register.

- Response Planning. Planning actions that must be taken to prevent or mitigate the negative risks (threats) and encourage the occurrence of positive risks (opportunities).

- Risk Monitoring and Control. Among the main activities that are performed in this process are implementations of plans in response to risks, monitoring identified risks, identification of new risks, updating risks register and risk management plan.

With this last process description, we conclude the general explanation of each one of processes included in the IT department chain of value. We consider that these processes are essential to perform an appropriate IT management within a medium or large size organization either it belongs to the public or private sector. 


\section{CLEI ELECTRONIC JOURNAL VOLUME 17 NUMBER 2 PAPER 3}

\section{Conclusions}

This article has described a model of business processes that specifies, in a concise manner, a complete set of processes for performing IT management in a medium or large size organization.

The definition of these processes is based on the enterprise architecture of the organization. It includes a comprehensive set of technical, managerial, and administrative processes that would be potentially feasible to implement in an organization of the size aforementioned; particularly, within the context of Venezuelan and Latin American public organizations and/or private.

The main contribution of this work is the description of a model of business processes for an IT department based on the EA. The model may be applied in three different ways:

1. As a framework or reference model for the design and standardization of the IT processes and services of an organization.

2. As an evaluation model to be used as a comparison pattern for evaluating and reengineering the existing IT management processes of an organization.

3. To support the organizational design or restructuring of the unit responsible for the IT Management in an organization.

A relevant feature of our model is that it describes the direct relationship between the IT processes and the business, information systems and technology architectures of an EA. We believe that this way of identifying, defining and organizing the processes of the IT organizational unit leads to a fully accomplishment of the business goals. Besides, the proposed process model in itself constitutes a means to implement effective organizational alignment strategies business/IT required by any organization.

Moreover, our process model integrates the different categories of technical, managerial, and administrative processes, which are common to any organizational unit, in contrast to the different proposals for the IT management mentioned in section 2. The main difference between our model and the one proposed by IBM [14] is the definition of the central element on which the models make emphasis. The IBM model emphasizes on the delivery of computer services and its management; whereas, our model emphasizes on the management of the EA, as the central point to determine levels of alignment between IT and business.

The model is actually used as a framework for process re-engineering and organizational redesign of the IT departments of two Venezuelan government organizations. In both cases, the implementation of the resulting IT management processes and the associated organizational structures has faced problems related with the resistance to change. Many employees, who are accustomed to execute processes in one way, react or resist to perform their tasks in a different way. It may be seeing as a natural reaction, since changes normally produce anxiety and uncertainty. In order to reduce these problems, we have recommended the implementation of a plan for managing resistance to change based on several strategies, such as conducting appropriate training, communicating the change, and empowering employees to contribute with the changes. The verification and validation of the model applicability, in the two aforementioned cases of study, will therefore take some time and remains as future work. Based on the results of model validation, it would be possible to define refinements on some of the sub-processes and their activities, as an adaptation in response to the organization needs and contexts of use.

\section{Acknowledgements}

This work is sponsored by the National Fund for Scientific and Technological Research (FONACIT) of Venezuela, under the project numbers G-2005000165 and PEI-2012001090. The company BIOSOFT C.A. (www.biosoftca.com) provided the infrastructure, cases of study and space needed to conduct the research.

\section{References}

[1] J. McAdams, "Seven common management obstacles", Computerworld, 2006.

[2] The Open Group, "The Open Group Architecture Framework (TOGAF) ", version 9, 2009. [Online]. Available at: http://www.opengroup.org/togaf/

[3] R. Sessions, Simple Architectures for Complex Enterprises, Redmond, WA: Microsoft Press, 2008. 


\section{CLEI ELECTRONIC JOURNAL VOLUME 17 NUMBER 2 PAPER 3}

[4] J. A. Zachman, "Framework for Information Systems Architecture", IBM Systems Journal, Vol. 26, Number 3, 1987.

[5] A. Croteau, and F. Bergeron, "An information technology trilogy: business strategy, technological deployment and organizational performance," The Journal of Strategic Information Systems, vol. 10, pp. 77-99, 2001.

[6] J. Luftman, "Assessing business-IT alignment maturity", Communications of AIS, vol. 4, 2000.

[7] U.S. Department of Defense DOD, "Department of Defense Architecture Framework, DODAF", version 2.0.2, 2010. [Online]. Available at: http://dodcio.defense.gov/dodaf20.aspx

[8] U.S. Department of the Treasury Chief Information Officer Council, "TEAF - Treasury Enterprise Architecture Framework", version 1, 2000.

[9] Mitre Corporation, Enterprise Architecture Body of Knowledge (EABOK). 2013 [Online]. Available at: http://www2.mitre.org/public/eabok/eabok.html

[10] APM Group Ltd, "Official ITIL web site", 2013. [Online]. Available at: http://www.itil-officialsite.com/

[11] Software Engineering Institute (SEI), "CMMI for development", version 1.3, Technical report CMU/SEI-2010TR-033, Carnegie Mellon, November 2010.

[12] ISACA, "COBIT 4.1: Framework for IT governance and control", 2013. [Online]. Available at: http://www.isaca.org/Knowledge-Center/cobit/Documents/COBIT-4-1-FR.pdf

[13] DAMA International, The DAMA guide to the Data Management Body of Knowledge, 1st. Edition, DAMA International, 2009.

[14] IBM Corporation, "Align IT with business goals using the IBM Process Reference Model for IT", IBM Service Management, 2008.

[15] G. S. Kearns and A. L. Lederer, "A resource-based view of strategic IT alignment: How knowledge sharing creates competitive advantage", Decision Sciences, Vol. 34, No. 1, pp. 1-29, 2003.

[16] J. Luftman, "Measure your business-IT alignment", Optimize: Business Execution Services for Magazine, Issue 26, 2003.

[17] B. H. Reich and K. M. Nelson, "In their own words: CIO visions about the future of in-house IT organizations", The DATA BASE for Advances in Information Systems, 34, pp. 28-44, 2003.

[18] R. Sabherwal and Y. E. Chan, "Alignment between business and IS strategies: A study of prospectors, analyzers, and defenders", Information Systems Research, Vol. 12, No. 1, pp. 11-33, 2001.

[19] A. Etien, "L'Ingénierie de l'alignement: concepts, modéles et processus. The ACEM méthode pour la correction et l'évolution d'systeme d'information aux processus d'entreprise", PhD thesis, Université Paris 1, Pantheon - Sorbonne, Paris, France, 2006.

[20] I. Gmati and S. Nurcan, "A framework for analyzing business/information system alignment requirements", International Conference on Enterprise Information Systems (ICEIS), Funchal, Portugal, pp. 512-516, 2007.

[21] S. J. Bleistein, K. Cox and J. Verner, "Strategic alignment in requirements analysis for organizational IT: an integrated approach", in 20th ACM Symposium on Applied Computing (SAC' 05), Santa Fe, USA, pp. 1300$1307,2005$.

[22] M. Rosemann, I. Vessey and R. Weber, "Alignment in enterprise systems implementations: the role of ontological distance", in Proceedings of the International Conference of Information Systems, Washington, D.C., USA, 12-15 December, pp. 439-447, 2004.

[23] C. Salinesi and C. Rolland, "Fitting business models to systems functionality exploring the fitness relationship", Proceedings of CAiSE'03, Velden, Austria, 2003.

[24] I. Gmati, "La méthode DEEVA (Design and Evolution Of Alignment)", Phd thesis, Université Paris 1, Pantheon - Sorbonne, Specialite : Informatique, Paris, France, 2001. 


\section{CLEI ELECTRONIC JOURNAL VOLUME 17 NUMBER 2 PAPER 3}

[25] J. Montilva and J. Barrios, "BMM: A Business Modeling Method for Information Systems Development", CLEI Electronic Journal, Vol. 7, No. 2, 2004.

[26] Object Management Group (OMG), "Business process model and notation (BPMN) ", version 2.0, 2011.

[27] H. E. Eriksson and M. Penker, Business modeling with UML: business patterns at work, New York: John Wiley \& Sons, 2000.

[28] J. Dugmore and S. Taylor, "ITIL V3 and ISO/IEC 20000", Alignment white paper, www.itilnews.org, 2008.

[29] M. Meijer, M. Smalley and S. Taylor, "ITIL V3 and ASL. Sound Guidance for Application. Management and Application Development", Alignment white paper, www.itilnews.org, 2008.

[30] Project Management Institute (PMI), The standard for portfolio management, Second edition, Project Management Institute, 2008a.

[31] Project Management Institute (PMI), The standard for program management, Second edition, Project Management Institute, 2008b.

[32] Project Management Institute (PMI), Guía de los fundamentos para la dirección de proyectos (Guía del PMBOK), Fourth edition, Project Management Institute, 2008.

[33] Institute of Electrical and Electronics Engineering (IEEE), "IEEE standard for software configuration management plans", IEEE Std 828-1998, USA, New York, 1998. 